\title{
Association between impulsivity and orthorexia nervosa / healthy orthorexia: any mediating effect of depression, anxiety, and stress?
}

Emmanuelle Awad ${ }^{1}$, Pascale Salameh ${ }^{2,3,4}$, Hala Sacre ${ }^{2}$, Diana Malaeb ${ }^{5,6}$, Souheil Hallit ${ }^{7,8^{*}}$ and Sahar Obeid ${ }^{2,9^{*+}+}$

\begin{abstract}
Background: There is a lack of studies investigating the possible mediating role of psychological factors, such as depression, anxiety and stress on orthorexic eating behaviors. Given that personality attributes might affect the manifestation of psychological disorders, it was hypothesized that depression, anxiety and stress mediate the relationship between impulsivity-related traits and orthorexic eating, noting that previous research had evaluated the role of depression as a mediator between impulsivity and other pathological eating behaviors. The study objectives were to explore the mediating effect of depression, anxiety, and stress, on impulsivity and orthorexia nervosa, and healthy orthorexia.
\end{abstract}

Methods: This cross-sectional study conducted between July and December 2019 recruited 519 Lebanese adults from seven community pharmacies randomly selected from a list provided by the Lebanese Order of Pharmacists.

Results: Our results showed that depression and anxiety were positively correlated with ON. We also found a notable gender difference in findings: higher anxiety and female gender were significantly associated with higher TOS healthy orthorexia, while higher stress was associated with lower TOS healthy orthorexia. Finally, higher urgency was associated with lower TOS healthy orthorexia, while higher perseverance was significantly associated with higher TOS healthy orthorexia. Depression and anxiety partially mediated the association between perseverance and $\mathrm{ON}$ while anxiety and stress partially mediated the association between urgency and healthy orthorexia.

Conclusion: Our study suggests that depression, anxiety and stress play a mediating role between impulsivity and orthorexia nervosa/healthy orthorexia. Our findings provide a ground for future investigations of impulsive behaviors, psychopathology, and orthorexia in different populations.

Keywords: Orthorexia nervosa, Healthy orthorexia, Anxiety, Depression, Stress, Impulsivity

\footnotetext{
* Correspondence: souheilhallit@hotmail.com; saharobeid23@hotmail.com

${ }^{\dagger}$ Souheil Hallit and Sahar Obeid share senior authorship.

${ }^{7}$ Faculty of Medicine and Medical Sciences, Holy Spirit University of Kaslik (USEK), Jounieh, Lebanon

${ }^{2}$ INSPECT-LB: Institut National de Santé Publique, Épidémiologie Clinique et Toxicologie-Liban, Beirut, Lebanon

Full list of author information is available at the end of the article
}

C C The Author(s). 2021 Open Access This article is licensed under a Creative Commons Attribution 4.0 International License, which permits use, sharing, adaptation, distribution and reproduction in any medium or format, as long as you give appropriate credit to the original author(s) and the source, provide a link to the Creative Commons licence, and indicate if changes were made. The images or other third party material in this article are included in the article's Creative Commons licence, unless indicated otherwise in a credit line to the material. If material is not included in the article's Creative Commons licence and your intended use is not permitted by statutory regulation or exceeds the permitted use, you will need to obtain permission directly from the copyright holder. To view a copy of this licence, visit http://creativecommons.org/licenses/by/4.0/ The Creative Commons Public Domain Dedication waiver (http://creativecommons.org/publicdomain/zero/1.0/) applies to the data made available in this article, unless otherwise stated in a credit line to the data. 


\section{Background}

Orthorexia Nervosa (ON) involves a dysfunctional preoccupation with consuming foods perceived as healthy and an extremely strict adherence to self-imposed diet restrictions [1]. Key elements of ON are "(a) obsessive focus on dietary practices believed to promote optimum wellbeing through healthy orthorexia (with inflexible dietary rules, recurrent and persistent preoccupations related to food, compulsive behaviors); and (b) consequent, clinically significant, impairment (e.g. medical or psychological complications, great distress, and/or impairment in important areas of functioning)" [2]. Unlike those with Anorexia Nervosa, individuals with $\mathrm{ON}$ are concerned with regulating food quality rather than their weight. $\mathrm{ON}$ can cause significant distress if the dietary rules are broken, as well as physical, psychological, and social impairment [3]. People with ON can become severely underweight, develop anxiety disorders and depression, and socially isolate themselves to avoid exposure to what they consider as impure nutrition [3]. Despite its adverse effects, $\mathrm{ON}$ is not included as an eating disorder in the Diagnostic and Statistical Manual of Mental Disorders- 5th edition (DSM-5) as of now [4]. Several diagnostic criteria of ON overlap with symptoms of other psychological disorders [2], such as obsessive-compulsive disorder (OCD) $[5,6]$ and Anorexia Nervosa (AN) [7], triggering discussions about its categorical classification [8]. Having said that, the essence differs between $\mathrm{ON}$ and $\mathrm{AN}$ : the main concern for orthorexic eating behaviors are health and purity while the core of AN is weight loss and food quantity [7]. On the other hand, some authors assume two different subtypes of orthorexia: $\mathrm{ON}$ and healthy orthorexia, characterized by the non-pathological fixation on consuming healthy foods. Key elements of healthy orthorexia are a "healthy interest in diet, healthy behavior with regard to diet, and eating healthily as part of one's identity" [9]. However, little research exists on its traits and associated factors, with the majority of the literature focusing on $\mathrm{ON}$.

\section{Orthorexia measures of assessment}

Various psychometric tools to measure ON were used, such as the Bratman Orthorexia test (BOT), Düsseldorfe Orthorexia scale (DOS), and different validated versions of the ORTO-15 and ORTO-11, the most used questionnaires to assess ON. The ORTO-15 received heavy criticism for its significant psychometric limitations [10]; thus, researchers developed alternative measures, such as the Teruel Orthorexia Scale (TOS), which includes items measuring both $\mathrm{ON}$ and Healthy Orthorexia (HeOr) [11]. ON consists of extreme focus on food intake and preoccupation with designing and following the optimal diet. Adherence to the diet is done by following strict dietary rules, subsequently causing distress and impairment (Cena et al., 2019). On the other hand, $\mathrm{HeOr}$ is the non-pathological dimension of orthorexia, which consist of placing importance on a healthy diet and lifestyle. Therefore, the prevalence varies depending on the instrument used and the population at study. In 2004, one of the first studies in Italy used ORTO-15 and showed a prevalence of $6.9 \%$ in a population of 404 students [12]. Another one using BOT in a sample of 283 dieticians found that $34.9 \%$ of the population had a high risk of ON [13]. A German study using the DOS on 446 university students reported a prevalence of $3.3 \%$, with a $9.0 \%$ risk of developing ON [14]. A recent study showed an orthorexia prevalence of $2.6 \%$ in Polish adults [15].

A previous study showed that the onset of restrictive eating disorders occurred earlier and these patterns were less severe for males as opposed to females [16, 17]. Females also exhibit more maladaptive eating symptomatology than men [18]. On the other hand, findings show that sex-specific hormones make women more vulnerable than men to suffer from maladaptive eating patterns at certain ages [19]. An association between education level and maladaptive eating patterns was found, with women who have lower education being more likely to suffer from eating disorders [20]. Differences were also found among men and women in their BMI: women with restrictive eating patterns had lower BMI compared to women who don't restrict, while men with restrictive eating patterns had a higher BMI compared to men who don't restrict [21]. These findings suggest the presence of gender differences in the presentation of maladaptive eating patterns.

\section{Impulsivity and eating styles}

Impulsivity has been used as a factor to assess and predict neuropsychological disorders [22]. The neurological processes behind impulsivity are clinically relevant to multiple psychological disorders, including eating disorders and OCD [23]. Research also found that latent neurobiological functions of impulsivity involve a broad range of psychological disorders, including OCD, eating disorders, depression, and anxiety disorders [24]. Furthermore, predisposing factors for depression and anxiety included impulsivity [25], while stress predicted risky and impulsive behaviors [26]. The neurological links between impulsivity, psychological disorders (including depression, anxiety, and stress), and obsessivecompulsive and eating disorders, suggest a possible relationship involving these variables.

Impulsivity encompasses different traits, each referring to a behavior: urgency (careless behavior), premeditation or purpose (the extent of planning), perseverance (determination), and risk (level of sensation seeking) [27]. Levels of impulsivity can differ among individuals with eating disorders and affect the way it is manifested [28]. The number of studies evaluating impulsivity, $\mathrm{ON}$ and healthy orthorexia is limited. Patients with eating 
disorders showed lower perseverance and higher urgency [29]. High harm avoidance (low risk-seeking) is associated with all eating disorders [30,31]. In addition, a previous study had revealed that impulsivity described a process in which high levels of negative urgency predicted more disordered eating, which would help manage negative affect (depression) [32]. As for healthy orthorexia, a recent study found that impulsivity was negatively associated with diet quality (fruit and vegetables, meat and poultry, processed meat, dairy products, milk-based desserts, and starchy foods) [33].

\section{Mental health and orthorexia}

Around half of the individuals who have restrictive eating patterns meet the criteria for Generalized Anxiety Disorder (GAD), and $15 \%$ of those who have eating disorders also have social phobia [34]. Major Depressive Disorder (MDD) and anxiety disorders, including GAD, were found as possible risk factors for developing ON [35]. As for healthy orthorexia, studies have long linked healthy diets, particularly those rich in fruits, vegetables, fish and whole grains, with a reduced risk of depression [36]. Furthermore, a previous study showed that $\mathrm{ON}$ was only partially associated with psychological problems such as depression, anxiety and stress, and this effect was moderated by healthy orthorexia in a German sample [37].

\section{Orthorexia in Lebanon}

Lebanon is a Middle-Eastern country, which has gone through political and war events that have affected the mental wellbeing of its residents, with high rates of depression [38], anxiety [39] and alexithymia [40] shown in recent studies. Different situations occurred in Lebanon (Lebanese civil war, protestation since 17 October 2019, Beirut Blast on 4 August 2020, the economic crisis in parallel with the COVID-19 pandemic) had many negative consequences on the mental health of the Lebanese population [41]. More particularly, in a sample of Lebanese adults, a total of $75.2 \%$ had a risk for developing $\mathrm{ON}$ [42]; yet, it is not commonly known or considered a disorder in this population. This number might be unrealistic since the validated ORTO-15 scale had low psychometric properties, which yielded a high prevalence of ON [43]. A recent study revealed an orthorexia prevalence of $8.4 \%$ in Lebanese adults using the Dusseldorf Orthorexia Scale [15]. Another study revealed that individuals from a Lebanese sample who met the criteria for ON experienced less psychological distress [44], but the literature connecting psychological distress to $\mathrm{ON}$ is scarce. A recent study among Lebanese medicine students found that higher anxiety was associated with lower ON tendencies and behaviors [44]. It was also found that behavioral problems related to eating habits were associated with impulsivity in the Lebanese population [45].

\section{Objective of the study and rationale}

Overall, the literature presents correlations with no inference of causation of either directions, or exploration of possible mediations for orthorexia. Given that previous research found that impulsivity, depression and anxiety symptoms may overlap and be associated with certain brain structures [46], it was hypothesized that depression, anxiety, or stress mediate the relationship between impulsivity-related traits and orthorexia dimensions in order to further explore the nature of these relationships (Fig. 1); noting that previous research had evaluated the role of depression as a mediator between impulsivity and eating disorders, however it did not include orthorexia [42].

Therefore, the objective of this study was to evaluate the association between impulsivity and orthorexia nervosa/healthy orthorexia after adjusting over sociodemographic variables and explore the mediating effect of depression, anxiety, and stress, on impulsivity and ON/ healthy orthorexia, using the Teruel Orthorexia Scale (TOS) was used to measure orthorexia nervosa and healthy orthorexia [34]. Particularly, the following hypotheses were concentrated on:

1. Correlations exist between impulsivity traits and orthorexia, sociodemographic variables and orthorexia, and mental health variables (depression, anxiety and stress) and orthorexia.

2. Different correlations exist between impulsivity traits, sociodemographic variables and mental health variables (depression, anxiety and stress) and both dimensions of orthorexia $\mathrm{ON}$ and $\mathrm{HeOr}$.

3. Mental health variables (depression, anxiety and stress) mediate the relationship between impulsivity traits (urgency, premeditation, perseverance and sensation seeking) and $\mathrm{ON}$ or $\mathrm{HeOr}$.

\section{Methods}

The sample comprised 519 adults $(n=283, \quad 56.0 \%$ women) with a median age of 33.50 years (mean: 36.02, standard deviation: 14.20, range: 18-75) and a median BMI of $24.21 \mathrm{~kg} / \mathrm{m}^{2}$ (mean: 24.41, standard deviation: 4.32, range: 17.01-37.78). More than half of the sample had university education level $(n=252,53.1 \%)$ and reported to be unmarried $(n=264,51.6 \%)$ (Table 1$)$.

\section{Procedure}

This cross-sectional study conducted between July and December 2019 recruited a sample of Lebanese adults from seven community pharmacies randomly selected from a list provided by the Lebanese Order of 


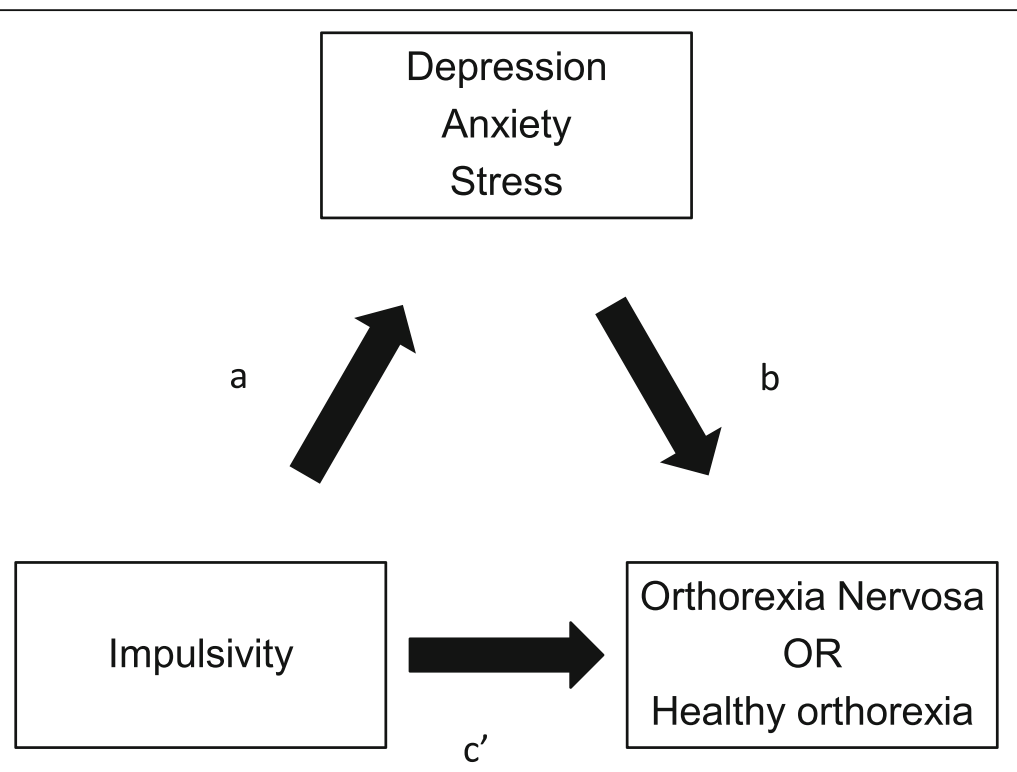

Fig. 1 a Supposed relation between impulsivity and depression, anxiety and stress; b Supposed relation between depression, anxiety, stress and orthorexia nervosa/heathy orthorexia; $\mathbf{c}^{\prime}$ Relation between impulsivity and orthorexia nervosa/heathy orthorexia

Pharmacists. Every person 18 years and above entering a pharmacy was eligible and encouraged to participate in the study. Well-trained personnel explained the study objectives to participants. Of the 700 questionnaires distributed, 520 (74.28\%) were completed and collected back. All

Table 1 Sociodemographic characteristics of the sample ( $N=$ 519)

\begin{tabular}{ll}
\hline Variable & N (\%) \\
\hline Gender & $222(44.0 \%)$ \\
Male & $283(56.0 \%)$ \\
Female & \\
Marital status & $232(45.4 \%)$ \\
Single & $247(48.3 \%)$ \\
Married & $17(3.3 \%)$ \\
Widowed & $15(2.9 \%)$ \\
Divorced & \\
Education level & $30(6.3 \%)$ \\
Primary & $74(15.6 \%)$ \\
Complementary & $119(25.1 \%)$ \\
Secondary & $252(53.1 \%)$ \\
University & \\
Monthly income & $138(29.5 \%)$ \\
No income & $148(31.6 \%)$ \\
$<1000$ USD & $133(28.4 \%)$ \\
1000-2000 USD & $49(10.5 \%)$ \\
\hline 2000 USD &
\end{tabular}

methods were carried out in accordance with relevant guidelines and regulations.

\section{Sample size calculation}

The G-power software calculated a minimum sample of 395 participants, based on an effect size $\mathrm{f} 2=2 \%$, an alpha error of $5 \%$, a power of $80 \%$, and taking into consideration 20 factors to be entered in the multivariable analysis.

\section{Questionnaire and variables}

The self-administered questionnaire was anonymous and available in Arabic, the mother tongue in Lebanon. It required 15-20 min to complete approximately.

The first part clarified socio-demographic characteristics: age, gender, level of education, and monthly income, in addition to weight (in $\mathrm{kg}$ ) and height (in meters) to calculate the Body Mass Index (BMI).

The second part included the Teruel Orthorexia Scale (TOS) [11], a relatively new tool consisting of 17 items rated on a 4-point Likert scale ranging from 0 (completely disagree) to 3 (completely agree). Validated in Lebanon $[47,48]$, this scale yields two subscale scores with related statements: $\mathrm{HeOr}$ (e. g., "My interest in healthy food is an important part of the way I am, of how I understand the world") and ON (e.g., "I am concerned about the possibility of eating unhealthy foods"), with higher scores indicating higher orthorexia nervosa/ healthy orthorexia.. Reliability was very good for both subscales $\left(\alpha_{\text {Cronbach }}=0.87\right)$. Permission was obtained from Dr. Juan-Ramon Barrada and Dr. Maria Roncero to 
use the scale in this study. The self-administered $\mathbf{I}-\mathbf{8}$ scale assessed urgency (e. g., "To make myself feel better, I sometimes do things I regret later."), premeditation (e. g., "I usually think carefully before I do anything"), perseverance (e. g., "I allocate my time well so that I can complete tasks on time."), and sensation risk (e. g., "I'm ready to take risks."). All items are rated from 0 (doesn't apply at all) to 5 (applies completely), with higher scores indicating higher impulsivity. In this study, the Cronbach's alpha values of the subscales were as follows: Perseverance: 0.802; urgency: 0.796; premeditation: 0.815 ; and sensation seeking: 0.613 [49].

Depression was assessed using the Hamilton Rating Scale for Depression (HAM-D), validated in Lebanon [50]. This scale includes 17 items such as depressed mood, feelings of guilt, suicide, insomnia, work and activities, somatic symptoms, weight and insight. Each item refers to specific depression symptomatology; it is rated from 0 to $2-4$, depending on the item, 2-4 being the most severe $\left(\alpha_{\text {Cronbach }}=0.871\right)$. Scores $<10$ indicate no depression, 10-13 mild depression; 14-17 mild to moderate depression; $>17$ moderate to severe depression. The questionnaire also consisted of the Hamilton Anxiety Rating Scale that assessed the level of anxiety. This tool validated in the Lebanese population [51] includes 14 items describing conditions such as anxious mood, insomnia, somatic symptoms, tension and respiratory symptoms. The items are rated from 0 to 4,4 being the most severe $\left(\alpha_{\text {Cronbach }}=0.917\right)$. Stress was measured using the Beirut Distress Scale (BDS10). This 10 -item tool has been recently validated in Lebanon to assess psychological distress [52]. The scale included statements such as: "I lost the desire to learn", "My mood changes for tiny matters" and "I worry about little things". Items are rated over a four-point Likert scale, with higher scores reflecting higher psychological distress $\left(\alpha_{\text {Cronbach }}=0.899\right)$.

\section{Forward and back translation procedure}

The translation procedure was done according to previous methods described in the literature [53-55]. A clinical psychologist, whose native language is Arabic and fluent in English, performed the forward translation for the I-8 scale. Two psychiatrists, a medical professional writer and the primary investigators verified the Arabic translated version. A backward translation was then performed by another psychologist, fluent in Arabic, and unfamiliar with the concepts of the scales. The back-translated English questionnaire was subsequently compared to the original English one by the principal investigator to discern discrepancies and solve any inconsistencies between the two versions. The process of forward and back-translation was repeated until all ambiguities disappeared. The questionnaire was pilot-tested on a sample of 20 participants before the data collection was officially started. The results of the pilot sample test were not included in the final datasheet.

\section{Statistical analysis}

A factor analysis was initiated to confirm the legitimacy of the construct of the I-8 scale in our sample using the FACTOR program; the Pearson correlation matrix was used, with a parallel analysis procedure for determining the number of factors to be retained. A varimax rotation was used since the items of the I-8 scale were not highly correlated. The Kaiser-Meyer-Olkin (KMO) measurement of sampling adequacy and Bartlett's sphericity test were appropriate. The factors retained corresponded to Eigenvalues greater than one. Statistical analysis was performed using SPSS software, version 23. Data were screened for missing and unrealistic values (e.g., aged 5, or BMI above $60 \mathrm{~kg} / \mathrm{m} 2$ or less than $16 \mathrm{~kg} / \mathrm{m} 2$ ) that were restored when possible, or otherwise considered missing. The normality of distribution of the TOS OrNe and OrHe scores were confirmed via a calculation of the skewness and kurtosis; values for asymmetry and kurtosis between -2 and +2 are considered acceptable in order to prove normal univariate distribution [56]. These conditions consolidate the assumptions of normality in samples larger than 300 [57]. Accordingly, the Student t-test was used to check for an association between TOS ON and healthy orthorexia scores and dichotomous variables (i.e., gender and marital status) while the ANOVA test was used to compare the TOS ON and healthy orthorexia means between three or more means (i.e., education level and monthly income). The Pearson correlation test was used to correlate two continuous variables (i.e., age, BMI, depression, anxiety, stress, and impulsivity). A multivariate analysis of covariance (MANCOVA) was carried out to compare multiple measures (TOS ON and healthy orthorexia scores taken as dependent variables) between the different factors, taking into account potential confounding variables: age, gender, education level, monthly income, and BMI.

\section{Mediation analysis}

The PROCESS SPSS Macro version 3.4 model four [58] was used to calculate three pathways. Pathway A determined the regression coefficient for the effect of impulsivity on depression/anxiety/stress, Pathway B examined the association between depression/anxiety/stress and $\mathrm{ON} /$ healthy orthorexia, independent of impulsivity, and Pathway $\mathrm{C}^{\prime}$ estimated the total and direct effect of impulsivity on ON/healthy orthorexia. Pathway AB calculated the indirect intervention effects (Fig. 1). To test the significance of the indirect effect, the macro generated 
bias-corrected bootstrapped 95\% confidence intervals (CI) [58]. A significant mediation was determined if the $\mathrm{CI}$ around the indirect effect did not include zero [58]. The covariates that were included in the mediation model were those that showed significant associations with $\mathrm{ON}$ in the bivariate analysis. $P<0.05$ was considered significant.

\section{Results}

\section{Description of the scores}

The mean scores for the TOS, depression, anxiety, and stress scores were as follows: TOS ON $7.75 \pm 5.62$, TOS healthy orthorexia $10.57 \pm 6.04$, depression $6.09 \pm 7.27$, anxiety $12.86 \pm 10.52$, and stress $17.34 \pm 4.60$.

\section{Factor analysis}

The total sample $(n=519)$ was used for the factor analysis of the I-8 scale items. The KMO value of 0.704 and the significant Bartlett's sphericity test $(p<0.001)$ ensured the adequacy of the model. All items of the I-8 scale were extracted; the observation of the scree plot and Eigen values higher than 1 suggested a four-factor solution, explaining $81.97 \%$ of the total variance. These four factors were labeled perseverance (Factor 1), urgency (Factor 2), premeditation (Factor 3) and sensation seeking (Factor 4) respectively. Finally, the $\alpha_{\text {Cronbach }}$ value was acceptable (0.641) (Table 2).

\section{Bivariate analysis}

A significantly higher mean TOS healthy orthorexia score was found in females compared to males and in married compared to single participants; whereas, none of these variables was significantly associated with TOS ON (Table 3).

Older age, BMI, anxiety, stress, urgency, and perseverance were significantly but weakly associated with higher TOS ON. Additionally, higher anxiety was significantly, but weakly, associated with higher TOS healthy orthorexia; whereas, higher BMI and perseverance were significantly, but weakly, associated with lower TOS healthy orthorexia (Table 4). It is noteworthy that premeditation and sensation-seeking were not significantly associated with $\mathrm{ON}$ and healthy orthorexia.

\section{Multivariate analysis}

Higher depression and anxiety were significantly associated with higher $\mathrm{ON}$, with none of the impulsivity subscales being associated with ON. Moreover, higher anxiety and female gender were significantly associated with higher TOS healthy orthorexia, while higher stress was significantly associated with lower TOS healthy orthorexia. Finally, higher urgency was associated with lower TOS healthy orthorexia, while higher perseverance was significantly associated with higher TOS healthy orthorexia (Table 5).

\section{Mediation analysis of orthorexia nervosa}

Depression and anxiety partially mediated the association between perseverance and $\mathrm{ON}$ by $8.08 \%$ (Fig. 2) and $14.65 \%$ (Fig. 3), respectively. Stress did not mediate the association between impulsivity and $\mathrm{ON}$.

\section{Mediation analysis of healthy orthorexia}

Depression did not mediate the association between impulsivity and healthy orthorexia. Anxiety and stress partially mediated the association between urgency and healthy orthorexia by $14.96 \%$ (Fig. 4) and $15.12 \%$ (Fig. 5), respectively. All details regarding the mediation analysis can be found in Supplementary Tables 1 and 2 .

\section{Discussion}

Our study showed that higher depression and higher anxiety were significantly associated with higher orthorexia nervosa, whereas the female gender and higher anxiety were significantly associated with

Table 2 Factor analysis of the I-8 impulsivity scale using the varimax rotation

\begin{tabular}{|c|c|c|c|c|}
\hline Variable & Factor 1 & Factor 2 & Factor 3 & Factor 4 \\
\hline $18-6$ & 0.919 & & & \\
\hline $18-5$ & 0.897 & & & \\
\hline $18-2$ & & 0.926 & & \\
\hline $18-1$ & & 0.904 & & \\
\hline $18-3$ & & & 0.994 & \\
\hline $18-4$ & & & 0.791 & \\
\hline $18-7$ & & & & 0.862 \\
\hline $18-8$ & & & & 0.844 \\
\hline Percentage of variance explained & 38.51 & 21.25 & 13.56 & 8.65 \\
\hline Cronbach's alpha & 0.802 & 0.796 & 0.815 & 0.613 \\
\hline
\end{tabular}

Factor 1 = perseverance; Factor 2 = urgency; Factor 3 = premeditation; Factor 4 = sensation seeking 
Table 3 Bivariate analysis of categorical and dichotomous variables associated with orthorexia nervosa

\begin{tabular}{|c|c|c|}
\hline Variable & TOS orthorexia nervosa & TOS healthy orthorexia \\
\hline \multicolumn{3}{|l|}{ Gender } \\
\hline Male & $7.35 \pm 5.65$ & $9.70 \pm 5.88$ \\
\hline Female & $8.00 \pm 5.66$ & $11.19 \pm 6.13$ \\
\hline$p$ & 0.204 & 0.006 \\
\hline \multicolumn{3}{|l|}{ Marital status } \\
\hline Single/divorced/widowed & $7.80 \pm 5.69$ & $9.80 \pm 6.08$ \\
\hline Married & $7.70 \pm 5.55$ & $11.40 \pm 5.89$ \\
\hline$p$ & 0.840 & 0.003 \\
\hline \multicolumn{3}{|l|}{ Education level } \\
\hline Illiterate/primary & $6.40 \pm 5.16$ & $9.43 \pm 5.65$ \\
\hline Complementary & $8.59 \pm 6.42$ & $10.20 \pm 7.15$ \\
\hline Secondary & $7.44 \pm 5.12$ & $9.58 \pm 5.49$ \\
\hline University & $7.53 \pm 5.89$ & $11.24 \pm 6.20$ \\
\hline $\mathrm{p}$ & 0.303 & 0.065 \\
\hline \multicolumn{3}{|l|}{ Monthly income } \\
\hline No income & $8.11 \pm 6.06$ & $10.26 \pm 6.47$ \\
\hline$<1000$ USD & $7.34 \pm 5.31$ & $10.43 \pm 6.15$ \\
\hline $1000-2000$ USD & $7.68 \pm 5.27$ & $10.94 \pm 5.77$ \\
\hline$>2000$ USD & $8.96 \pm 6.50$ & $11.86 \pm 5.52$ \\
\hline $\mathrm{p}$ & 0.328 & 0.398 \\
\hline \multicolumn{3}{|c|}{$\begin{array}{l}\text { This table presents the mean } \pm \text { standard deviations of the associations } \\
\text { between each independent variable and the orthorexia nervosa/healthy } \\
\text { orthorexia scores. The Student t-test was used to compare between orthorexia } \\
\text { nervosa/healthy orthorexia scores and gender and marital status, whereas the } \\
\text { ANOVA test was used to compare between orthorexia nervosa/healthy } \\
\text { orthorexia scores and education level and monthly income }\end{array}$} \\
\hline
\end{tabular}

higher TOS healthy orthorexia. Present findings also showed that higher stress was significantly associated with lower TOS healthy orthorexia. In addition, depression and anxiety played a partial mediating role between perseverance and $\mathrm{ON}$, while anxiety and stress partially mediated the relationship between urgency and healthy orthorexia.

\section{Sociodemographic characteristics and orthorexia}

Our results showed that the female gender was significantly associated with healthy orthorexia, in agreement with those of previous findings revealing that women scored higher on healthy orthorexia [59]. A previous study had found a correlation between the female gender and restrained eating, but its relation with healthy orthorexia was insignificant [59], while another did not find any significant differences between genders regarding healthy orthorexia [9]. Women reported more orthorexic behaviors than men cross-culturally [60], as they are under considerably higher societal pressure to follow a restrictive diet and health-based behaviors than males [61]. The reason behind a higher prevalence of restrictive eating disorders among women is clear: the ideal thin body type [62]. However, this may not apply in the case of orthorexic eating behaviors, as the objective is not weight loss but maintaining a strictly healthy diet. A previous study showed that women are more likely to maintain health through good dietary habits while men do so through physical exercise [63]; this could explain why women in our sample present more orthorexic behaviors.

Table 4 Bivariate analysis of continuous variables associated with orthorexia nervosa and healthy orthorexia

\begin{tabular}{|c|c|c|c|c|c|c|c|c|c|c|c|}
\hline Variable & $\begin{array}{l}\text { TOS } \\
\text { orthorexia } \\
\text { nervosa }\end{array}$ & $\begin{array}{l}\text { TOS healthy } \\
\text { orthorexia }\end{array}$ & Age & BMI & Depression & Anxiety & Stress & $\begin{array}{l}\text { I8 } \\
\text { urgency }\end{array}$ & $\begin{array}{l}18 \\
\text { premeditation }\end{array}$ & $\begin{array}{l}18 \\
\text { perseverance }\end{array}$ & $\begin{array}{l}\text { I8 } \\
\text { sensation } \\
\text { seeking }\end{array}$ \\
\hline TOS OrNe & 1 & & & & & & & & & & \\
\hline TOS HeOr & $.71^{\mathrm{a}}$ & 1 & & & & & & & & & \\
\hline Age & $.12^{\mathrm{a}}$ & .01 & 1 & & & & & & & & \\
\hline $\begin{array}{l}\text { Body mass } \\
\text { index }\end{array}$ & $.09^{c}$ & $-.08^{c}$ & $.40^{\mathrm{a}}$ & 1 & & & & & & & \\
\hline Depression & .03 & .02 & .07 & $.13^{b}$ & 1 & & & & & & \\
\hline Anxiety & $.29^{\mathrm{a}}$ & $.15^{\mathrm{b}}$ & -.02 & .06 & $.48^{\mathrm{a}}$ & 1 & & & & & \\
\hline Stress & $.11^{\mathrm{b}}$ & -.04 & $.12^{\mathrm{b}}$ & -.07 & $.19^{\mathrm{a}}$ & $.29^{a}$ & 1 & & & & \\
\hline 18 urgency & $.20^{\mathrm{b}}$ & -.07 & $-.19^{\mathrm{a}}$ & -.08 & .06 & $.17^{\mathrm{a}}$ & $.22^{\mathrm{a}}$ & 1 & & & \\
\hline $\begin{array}{l}18 \\
\text { premeditation }\end{array}$ & .07 & -.05 & $-.16^{\mathrm{a}}$ & -.06 & -.07 & .08 & $.21^{\mathrm{a}}$ & $.13^{c}$ & 1 & & \\
\hline $\begin{array}{l}18 \\
\text { perseverance }\end{array}$ & $.14^{\mathrm{a}}$ & $-.10^{\mathrm{b}}$ & $-.16^{\mathrm{a}}$ & .01 & -.02 & $.10^{c}$ & $.16^{\mathrm{a}}$ & $.18^{\mathrm{a}}$ & $.57^{\mathrm{a}}$ & 1 & \\
\hline $\begin{array}{l}\text { I8 sensation } \\
\text { seeking }\end{array}$ & -.06 & .01 & -.02 & .02 & .01 & $-.11^{c}$ & $-.10^{c}$ & .05 & $-.26^{a}$ & $-.32^{\mathrm{a}}$ & 1 \\
\hline
\end{tabular}


Table 5 Multivariate analysis (MANCOVA) taking TOS orthorexia nervosa and healthy orthorexia as dependent variable and each impulsivity subscale as an independent variable

\begin{tabular}{|c|c|c|c|c|c|c|c|c|}
\hline \multirow{2}{*}{\multicolumn{4}{|c|}{$\frac{\text { TOS orthorexia nervosa }}{\text { Model 1: } 18 \text { urgency score taken as an independent variable. }}$}} & 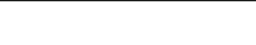 & \multicolumn{4}{|c|}{ TOS healthy orthorexia } \\
\hline & & & & & & & & \\
\hline Variable & Beta & $\mathbf{p}$ & $95 \% \mathrm{Cl}$ & Partial Eta Squared & Beta & $\mathrm{p}$ & $95 \% \mathrm{Cl}$ & Partial Eta Squared \\
\hline Depression & -0.124 & 0.005 & $-0.211--0.038$ & 0.019 & & & & \\
\hline Anxiety & 0.187 & $<0.001$ & $0.128-0.246$ & 0.087 & 0.145 & $<0.001$ & $0.081-0.210$ & 0.046 \\
\hline Stress & & & & & -0.162 & 0.018 & $-0.295--0.028$ & 0.014 \\
\hline 18 urgency & 0.120 & 0.599 & $-0.328-0.568$ & 0.001 & -0.668 & 0.007 & $-1.156--0.180$ & 0.017 \\
\hline Gender (females vs males*) & & & & & 1.416 & 0.018 & $0.245-2.587$ & 0.014 \\
\hline \multicolumn{9}{|c|}{ Model 2: 18 premeditation score taken as an independent variable. } \\
\hline Variable & Beta & $\mathbf{p}$ & $95 \% \mathrm{Cl}$ & Partial Eta Squared & Beta & $\mathrm{p}$ & $95 \% \mathrm{Cl}$ & Partial Eta Squared \\
\hline Depression & -0.123 & 0.006 & $-0.211--0.036$ & 0.019 & & & & \\
\hline Anxiety & 0.191 & $<0.001$ & $0.131-0.251$ & 0.089 & 0.142 & $<0.001$ & $0.076-0.207$ & 0.043 \\
\hline Stress & & & & & -0.178 & 0.01 & $-0.315--0.042$ & 0.016 \\
\hline 18 premeditation & -0.238 & 0.358 & $-0.747-0.271$ & 0.002 & 0.426 & 0.133 & $-0.130-0.983$ & 0.006 \\
\hline Gender (females vs males*) & & & & & 1.348 & 0.025 & $0.170-2.525$ & 0.012 \\
\hline \multicolumn{9}{|c|}{ Model 3: 18 perseverance score taken as an independent variable. } \\
\hline Variable & Beta & $\mathbf{p}$ & $95 \% \mathrm{Cl}$ & Partial Eta Squared & Beta & $\mathrm{p}$ & $95 \% \mathrm{Cl}$ & Partial Eta Squared \\
\hline Depression & -0.126 & 0.004 & $-0.213--0.040$ & 0.02 & & & & \\
\hline Anxiety & 0.186 & $<0.001$ & $0.126-0.246$ & 0.084 & 0.140 & $<0.001$ & $0.075-0.206$ & 0.042 \\
\hline Stress & & & & & -0.166 & 0.016 & $-0.301--0.032$ & 0.014 \\
\hline 18 perseverance & -0.456 & 0.061 & $-0.933-0.021$ & 0.009 & 0.603 & 0.023 & $0.082-1.125$ & 0.013 \\
\hline $\begin{array}{l}\text { Marital status } \\
\quad(\text { married vs single*) }\end{array}$ & & & & & 1.472 & 0.029 & $0.155-2.789$ & 0.012 \\
\hline \multicolumn{9}{|c|}{ Model 4: 18 sensation seeking score taken as an independent variable. } \\
\hline Variable & Beta & $\mathrm{p}$ & $95 \% \mathrm{Cl}$ & Partial Eta Squared & Beta & $p$ & $95 \% \mathrm{Cl}$ & Partial Eta Squared \\
\hline Depression & -0.131 & 0.003 & $-0.218--0.044$ & 0.021 & & & & \\
\hline Anxiety & 0.191 & $<0.001$ & $0.131-0.251$ & 0.088 & 0.132 & $<0.001$ & $0.067-0.198$ & 0.037 \\
\hline Stress & & & & & -0.183 & 0.007 & $-0.317--0.050$ & 0.018 \\
\hline 18 sensation seeking & 0.039 & 0.880 & $-0.465-0.542$ & 0.001 & 0.085 & 0.761 & $-0.464-0.634$ & 0.001 \\
\hline Gender (females vs males*) & & & & & 1.353 & 0.024 & $0.180-2.525$ & 0.012 \\
\hline
\end{tabular}

\section{Depression, anxiety, stress, and orthorexia}

Higher depression was associated with higher $\mathrm{ON}$ in the present study. These findings are consistent with previous studies that showed a higher prevalence of $\mathrm{ON}$ among individuals with depressive traits [64]. It can be hypothesized that orthorexic behavior can result in obsessive eating habits and lead to social isolation, which is in line with behavior associated with depression: depressive symptoms could be manifested by decreased interest in almost all activities [65]. If this line of thought is followed through, the pattern observed by clinicians that orthorexia is indeed accompanied by psychological distress and strain can be supported [64].

Furthermore, higher anxiety scores in our study were associated with both $\mathrm{ON}$ and healthy orthorexia, consistent with previous findings showing that anxiety predicted orthorexic behaviors [66]. Also, psychological fear and anxiety were associated with restrictive eating patterns [67], explained by the high levels of physical and health-related anxiety in individuals with ON [68] [69]. ,This outcome is coherent, as orthorexia consists of a preoccupation with eating healthy foods, although the process is extreme and causes anxiety in ON. On the other hand, restrictive eating patterns such as orthorexia can be motivated by anxiety related to health and possible detrimental outcomes from a poor diet or the consumption of unfavorable foods [70]. It is important to mention that anxiety occurs among individuals with maladaptive eating patterns such as $\mathrm{ON}$ as well as individuals with normal eating patterns such as healthy orthorexia but levels of anxiety differ [7], which supports our present findings. 


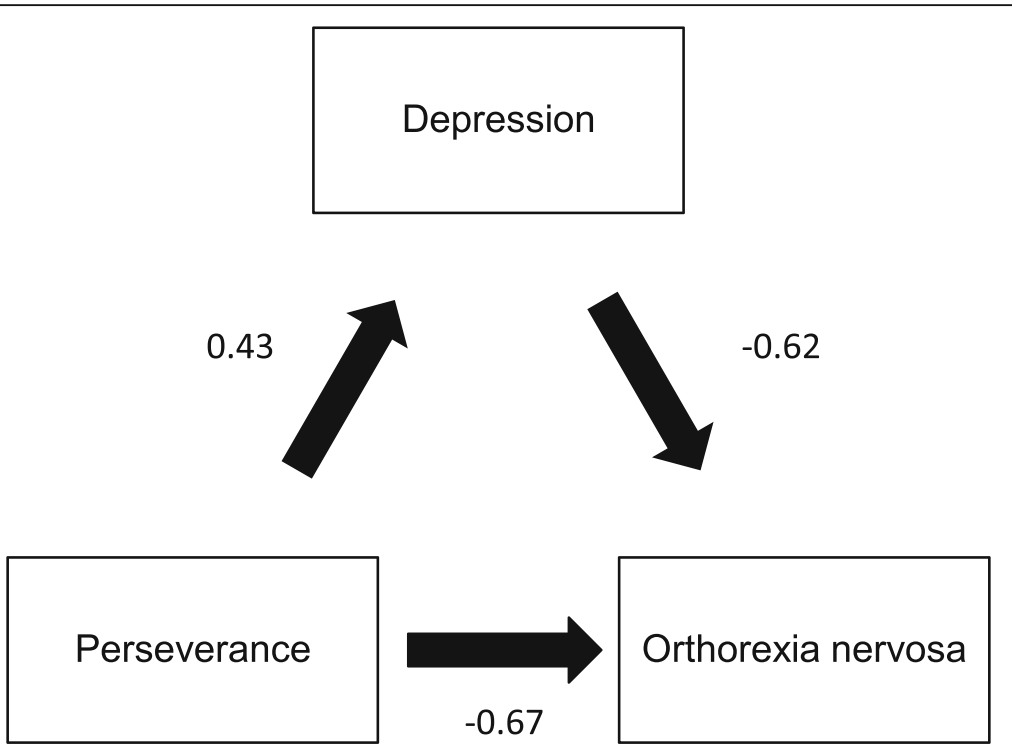

Fig. 2 Relation between perseverance and orthorexia nervosa, mediated by depression (numbers in the figure refer to standard coefficients)

Our results also showed that higher levels of stress were associated with lower TOS healthy orthorexia, which is similar to previous studies showing that higher stress was associated with pathological and restrictive eating behaviors [71] and negatively correlated with healthy orthorexia, an adaptive eating lifestyle. Another study confirmed that people with higher scores of ON eating behaviors, suggesting pathological occupation with maintaining a healthy diet, have higher levels of anxiety, stress, and depressive symptoms [70], which could a negative relationship between stress and healthy orthorexia behaviors. It is hypothesized that the preoccupation and worries about eating unhealthy foods and of the effect of food quality and composition on physical or emotional health or both, can lead to higher levels of stress; it is also implied by items of the TOS such as "I am concerned about the possibility of eating unhealthy foods" (Barrada \& Roncero, 2019). Furthermore, concern with the quality of one's diet is present in both orthorxia nervosa and healthy orthorexia, which
$-0.52$

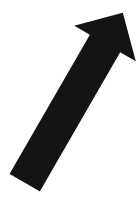

Anxiety

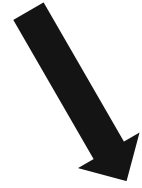

$-0.62$

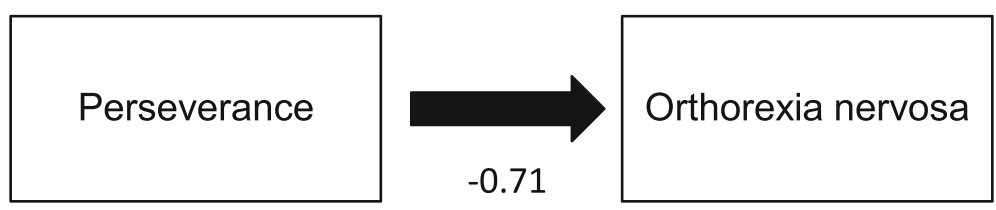

Fig. 3 Relation between perseverance and orthorexia nervosa, mediated by anxiety (numbers in the figure refer to standard coefficients) 


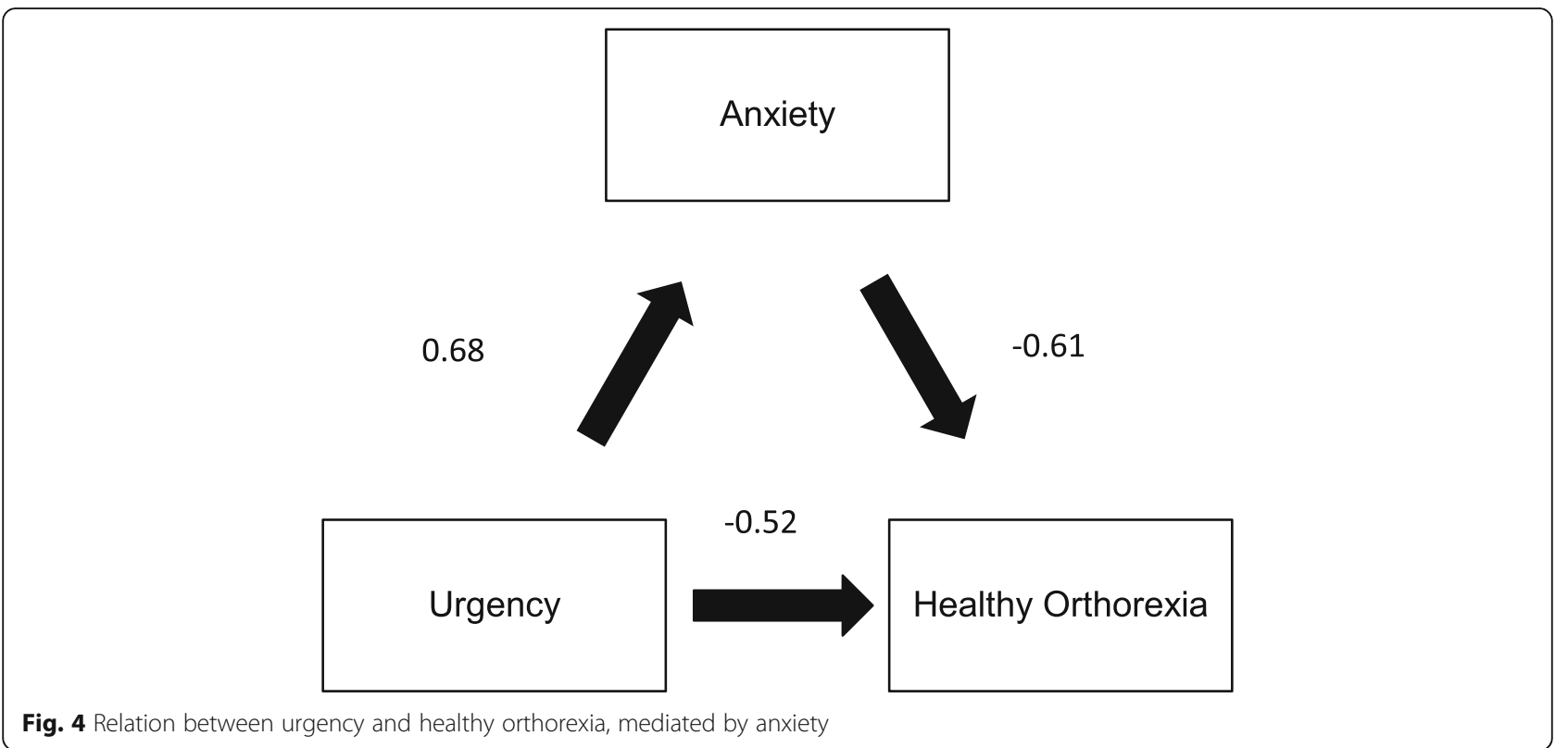

can be assumed to cause stress or be the result of a certain stress level; however, we can hypothesize that a certain stress level can cause adaptive behaviors such as healthy orthorexia. Stress can be placed on a continuum of different levels, which trigger behaviors that can be adaptive or maladaptive [71]. This can be examined in future research about differences in stress levels and eating patterns.

\section{Impulsivity and healthy orthorexia}

Higher urgency, associated with careless behavior, was correlated with lower TOS healthy orthorexia in our study. Healthy orthorexia is the non-pathological eating patterns [7], while urgency is linked to eating disorders [62]. Additionally, higher perseverance was associated with higher TOS healthy orthorexia in our study. Patients with eating disorders reported lower perseverance scores than those with restrictive behaviors [63]. Healthy orthorexia is a well-adjusted way of eating; results from eating disorders can be used as a reference for the anticipated associated variables with healthy orthorexia: we might hypothesize that impulsivity trait levels might differ between pathological and adaptive eating patterns. Healthy orthorexia is characterized by the adaptive determination to consume healthy foods, which could be comparable to perseverance trait, as opposed to pathological eating, which is predicted by the inability to inhibit emotional responses associated with pathological eating behaviors [69].

\section{Mediation between impulsivity and ON}

Our results showed that depression and anxiety were partial mediators between perseverance and ON. A previous study had confirmed that anxiety mediated between $\mathrm{ON}$ and cultural expectations, but not personality traits, such as elements of impulsivity [69]. Perseverance, the persistently pursuing a goal despite adverse outcomes, is associated with less ON scores, which is inconsistent with the proposed diagnostic criteria of $\mathrm{ON}$, where individuals continuously follow dietary rules despite physical, psychological, and social repercussions [3]. Another study showed that restriction-centered eating disorders are associated with low levels of perseverance and confirmed the predictive role of impulsivity traits in eating disorder [16]. Whether impulsivity-related traits affect the outcome, namely $\mathrm{ON}$, might depend on the levels of depression and anxiety of each individual.

\section{Mediation between impulsivity and healthy orthorexia}

In the present study, anxiety and stress were both partial mediators between urgency and healthy orthorexia. This impulsivity trait, i.e., urgency, is inconsistent with healthy orthorexia that focuses on maintaining a healthy diet. The partial mediating role played by psychological factors, such as anxiety and stress, might suggest that additional determinants could affect the pathway between having an eating disorder $(\mathrm{ON})$ or a normal pattern (healthy orthorexia) that could account for a more significant effect between impulsivity and ON. Psychological variables could influence whether levels of impulsivity-related traits contribute to some maladaptive or adaptive eating patterns. Our findings could determine partial mediation, which suggests the intervention of additional elements not discussed within our model. Furthermore, we were not able to find significant results with impulsivity, perseverance, purpose, and risk as 


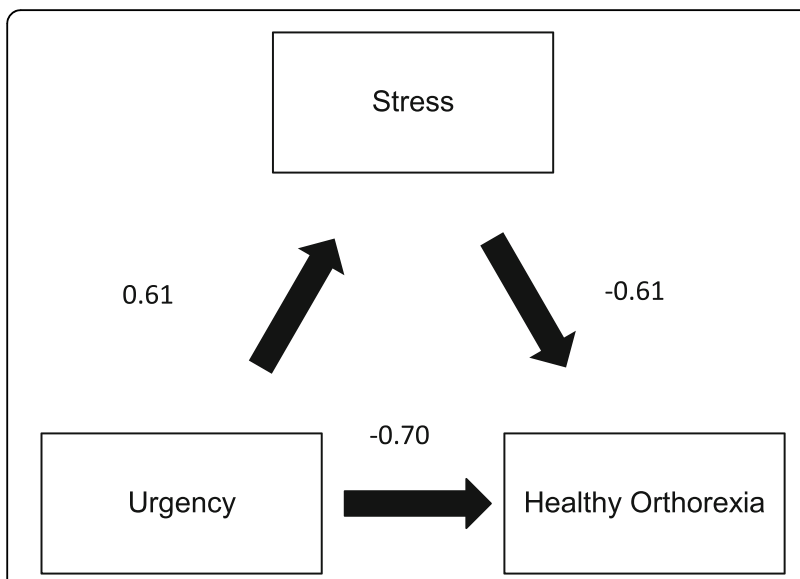

Fig. 5 Relation between urgency and healthy orthorexia, mediated by anxiety

independent variables, and depression, anxiety, and stress as mediators with $\mathrm{ON}$ and healthy orthorexia, highlighting the need for further research about ON, healthy orthorexia, and their associated variables.

\section{What is already known on this subject?}

Healthy orthorexia is generally considered equivalent to $\mathrm{ON}$ in the literature, despite evidence proving orthorexia is bidimensional and encompasses both healthy and pathological aspects. Similarly to ON, no diagnostic criteria or clear set of signs other that previously suggestions exist for healthy orthorexia, however, it is defined as non-disordered commitment to consuming healthy foods. Currently, ON is not qualified as an eating disorder due to insufficient clinical pertinence, therefore, little is known about healthy orthorexia other than information based on knowledge of $\mathrm{ON}$.

\section{What does this study add?}

Our study provides insight on impulsivity, orthorexia dimensions and psychological disorders, as well as sociodemographic correlates and mediating relationships. Considering that orthorexia is a newly emerging eating disorder that has not yet been included as a legitimate pathology, along with the fact that healthy orthorexia has not been separated from $\mathrm{ON}$ in many studies, our findings provide a pathway for further investigations regarding impulsive behaviors, psychopathology, and orthorexia (healthy orthorexia and $\mathrm{ON}$ ) in different populations.

\section{Clinical implications}

Our study adds to the limited body of research revolving around the relationship between impulsivity and ON, impulsivity and healthy orthorexia, the presence of a mediating role played by depression, anxiety, and stress, and $\mathrm{ON}$ and healthy orthorexia in general. Our results emphasize the importance of impulsivity-related traits in $\mathrm{ON}$; further research might evaluate $\mathrm{ON}$ as a consequence of impulsivity in clinical settings. Understanding this correlation and mediation in eating disorders would help develop treatment and preventive intervention guidelines. Moreover, understanding the personality traits of people with $\mathrm{ON}$ allows improving the prediction of people at risk of developing ON. Identifying problematic features of this disorder can also be translated into improved interventions. Our findings also highlight the possible comorbidities of ON. Pathological eating patterns are associated with depression, anxiety, and stress, which legitimatizes its relation with $\mathrm{ON}$ and might give clinicians motivation to observe it more carefully among patients.

\section{Limitations and strengths}

Our study has some limitations. Causation cannot be inferred due to its cross-sectional design. Second, the TOS and I-8 scales have yet to be validated to the Lebanese population; however, both were translated to Arabic for this study. Information bias might exist, as participants may have misinterpreted a question, thus decreasing the validity of the response. The scarcity of studies exploring the mediating role of psychological factors between impulsivity and orthorexia limited our discussion; hence, it was based on hypotheses. Although significant, the correlations obtained were weak. Residual confounding bias is also possible since not all factors associated with orthorexia dimensions were taken into consideration in this study. Religion was not taken into consideration in this study; the majority of the Lebanese population is composed of Muslims who may follow different dietary habits than Christians. Participants have not been screened for eating disorders before the start of the data collection. The influences of any cultural and linguistic differences between Spanish and Lebanese populations were not taken into consideration, which might have changed the results of this study. If the Bonferroni correction were to be applied to the statistical analysis, some variables that have been considered to be significantly associated with the dependent variables (such as BMI and stress in case of orthorexia nervosa and gender, BMI and perseverance in case of healthy orthorexia) must have been removed. Thus, these variables are unstable, warranting further confirmation in future studies. No evaluation of the overlap in the definition and content of the construct measured in the TOS was done; future studies should tackle this idea to compare the Spanish and Lebanese populations in this regard. On the other hand, the random sampling method used to select our participants allows the generalization of our results to the Lebanese population. 


\section{Conclusion}

The purpose of our study was to investigate possible correlations and mediation roles between impulsivity traits, mental health traits and both Orthorexia dimensions. Significant differences were found between $\mathrm{ON}$ and HeOr, and gender and relationship status, as well as significant correlations between impulsivity traits, mental health traits and $\mathrm{ON}$ or HeOr. Also, our study showed that depression and anxiety played a partial mediating role between perseverance and orthorexia nervosa, while anxiety and stress partially mediated the relationship between urgency and healthy orthorexia. Our findings provide a ground for future investigations of impulsive behaviors, psychopathology, and orthorexia in different populations.

\section{Abbreviations}

HeOr: Healthy orthorexia; TOS: Teruel Orthorexia Scale; ON: Orthorexia Nervosa; DSM-5: Diagnostic and Statistical Manual of Mental Disorders- 5th edition; OCD: Obsessive-compulsive disorder; MDD: Major Depressive Disorder; GAD: Generalized Anxiety Disorder; HAM-D: Hamilton Rating Scale for Depression; BDS: Beirut Distress Scale; KMO: Kaiser-Meyer-Olkin; MANCOVA: Multivariate analysis of covariance

\section{Supplementary Information}

The online version contains supplementary material available at https://doi. org/10.1186/s12888-021-03594-4.

\section{Additional file 1.}

\section{Acknowledgments}

The authors would like to thank all participants.

\section{Authors' contributions}

PS, HS, SO and SH conceived and designed the survey. SH and PS were involved in the statistical analysis and data interpretation. EA wrote the manuscript. DM involved in the data collection. HS reviewed the manuscript and edited the paper for English language. All authors read the manuscript, critically revised it for intellectual content, and approved the final version.

\section{Funding}

None.

\section{Availability of data and materials}

Data cannot be shared publicly because of the restrictions of the ethics committee. Data are available upon a reasonable request to the corresponding author for researchers who meet the criteria for access to confidential data.

\section{Declarations}

\section{Ethics approval and consent to participate}

Written informed consent was obtained from all participants. The study was approved by the ethics committees of the Psychiatric Hospital of the Cross (reference: HPC-13-2019). Participants were not compensated.

\section{Consent for publication}

Not applicable.

\section{Competing interests}

The authors have no conflicts of interest to report.

\section{Author details}

${ }^{1}$ Faculty of Social Sciences, Psychology Department, Lund University, Lund, Sweden. ${ }^{2}$ INSPECT-LB: Institut National de Santé Publique, Épidémiologie
Clinique et Toxicologie-Liban, Beirut, Lebanon. ${ }^{3}$ Faculty of Pharmacy, Lebanese University, Hadat, Lebanon. ${ }^{4}$ University of Nicosia Medical School, Nicosia, Cyprus. ${ }^{5}$ School of Pharmacy, Lebanese International University, Beirut, Lebanon. ${ }^{6}$ Life Sciences and Health Department, Paris-Est University, Paris, France. ${ }^{7}$ Faculty of Medicine and Medical Sciences, Holy Spirit University of Kaslik (USEK), Jounieh, Lebanon. ${ }^{8}$ Research Department, Psychiatric Hospital of the Cross, Jal Eddib, Lebanon. ${ }^{9}$ Psychology Department, Faculty of Arts and Sciences, Holy Spirit University of Kaslik (USEK), Jounieh, Lebanon.

Received: 22 June 2021 Accepted: 8 November 2021

Published online: 03 December 2021

\section{References}

1. Obeid S, Hallit S, Akel M, et al. Orthorexia nervosa and its association with alexithymia, emotion dysregulation and disordered eating attitudes among Lebanese adults. Eat Weight Disord. 2021. https://doi.org/10.1007/s40519021-01112-9.

2. Cena H, Barthels F, Cuzzolaro M, Bratman S, Brytek-Matera A, Dunn T, et al. Definition and diagnostic criteria for orthorexia nervosa: a narrative review of the literature. Eat Weight Disord. 2019;24(2):209-46. https://doi.org/10.1 007/s40519-018-0606-y.

3. Dunn TM, Bratman S. On orthorexia nervosa: a review of the literature and proposed diagnostic criteria. Eat Behav. 2016;21:11-7. https://doi.org/10.101 6/j.eatbeh.2015.12.006.

4. Simpson CC, Mazzeo SE. Attitudes toward orthorexia nervosa relative to DSM-5 eating disorders. Int J Eat Disord. 2017;50(7):781-92. https://doi.org/1 $0.1002 /$ eat.22710

5. McComb SE, Mills JS. Orthorexia nervosa: a review of psychosocial risk factors. Appetite. 2019;140:50-75. https://doi.org/10.1016/j.appet.2019.05.005.

6. Brytek-Matera A, Staniszewska A, Hallit S. Identifying the profile of orthorexic behavior and "normal" eating behavior with cluster analysis: a crosssectional study among polish adults. Nutrients. 2020;12(11). https://doi.org/1 0.3390/nu12113490

7. Awad E, Salameh P, Sacre H, Malaeb D, Hallit S, Obeid S. Association between impulsivity and healthy orthorexia: any moderating role of personality traits? Psychol Health Med. 2021;1-10:1-10. https://doi.org/10.1 080/13548506.2021.1954673.

8. Strahler J, Stark R. Perspective: classifying orthorexia nervosa as a new mental illness-much discussion, little evidence. Adv Nutr. 2020;11(4):784-789.

9. Depa J, Barrada JR, Roncero M. Are the motives for food choices different in orthorexia nervosa and healthy orthorexia? Nutrients. 2019;11(3). https://doi. org/10.3390/nu11030697.

10. Roncero $M$, Barrada JR, Perpiñá C. Measuring orthorexia nervosa: psychometric limitations of the ORTO-15. Span J Psychol. 2017;20:E41. https://doi.org/10.1017/sjp.2017.36.

11. Barrada J, Roncero M. Bidimensional structure of the orthorexia: development and initial validation of a new instrument. Anal Psicol. 2018; 34(2):282-90. https://doi.org/10.6018/analesps.34.2.299671.

12. Donini LM, Marsili D, Graziani MP, Imbriale M, Cannella C. Orthorexia nervosa: a preliminary study with a proposal for diagnosis and an attempt to measure the dimension of the phenomenon. Eat Weight Disord. 2004; 9(2):151-7. https://doi.org/10.1007/BF03325060.

13. Mathieu J. What is orthorexia? J Am Diet Assoc. 2005;105(10):1510-2. https://doi.org/10.1016/j.jada.2005.08.021.

14. Depa J, Schweizer J, Bekers SK, Hilzendegen C, Stroebele-Benschop N. Prevalence and predictors of orthorexia nervosa among German students using the 21-item-DOS. Eat Weight Disord. 2017;22(1):193-9. https://doi. org/10.1007/s40519-016-0334-0.

15. Brytek-Matera A, Sacre H, Staniszewska A, Hallit S. The prevalence of orthorexia nervosa in polish and Lebanese adults and its relationship with sociodemographic variables and BMI ranges: a cross-cultural perspective. Nutrients. 2020:12(12). https://doi.org/10.3390/nu12123865.

16. Claes L, Vandereycken W, Vertommen H. Impulsivity-related traits in eating disorder patients. Personal Individ Differ. 2005;39(4):739-49. https://doi.org/ 0.1016/j.paid.2005.02.022

17. Striegel Moore RH, Rosselli F, Perrin N, DeBar L, Wilson GT, May, A, Kraemer, HC. Gender difference in the prevalence of eating disorder symptoms. Int J Eat Disord. 2009;42(5):471-474.

18. Strahler J. Sex differences in orthorexic eating behaviors: A systematic review and meta-analytical integration. Nutrition. 2019;67:110534. 
19. Mikhail ME, Culbert KM, Sisk CL, Klump KL. Gonadal hormone contributions to individual differences in eating disorder risk. Curr Opin Psychiatry. 2019; 32(6):484.

20. Maxwell M, Thornton LM, Root TL, Pinheiro AP, Strober M, Brandt $H_{1} .$. Bulik CM. Life beyond the eating disorder: Education, relationships, and reproduction. Int J Eat Disord. 2011:44(3):225-232.

21. Poínhos R, Oliveira BM, Correia F. Eating behaviour patterns and BMI in Portuguese higher education students. Appetite. 2013;71:314-320.

22. Bland AR, Roiser JP, Mehta MA, Schei T, Boland H, Campbell-Meiklejohn DK, et al. EMOTICOM: a neuropsychological test battery to evaluate emotion, motivation, impulsivity, and social cognition. Front Behav Neurosci. 2016;10:25.

23. Robbins TW, Gillan CM, Smith DG, de Wit S, Ersche KD. Neurocognitive endophenotypes of impulsivity and compulsivity: towards dimensional psychiatry. Trends Cogn Sci. 2012;16(1):81-91. https://doi.org/10.1016/j.tics.2 011.11.009.

24. Chamberlain SR, Stochl J, Redden SA, Grant JE. Latent traits of impulsivity and compulsivity: toward dimensional psychiatry. Psychol Med. 2018;48(5): 810-21. https://doi.org/10.1017/S0033291717002185.

25. Caspi A, Houts RM, Belsky DW, Goldman-Mellor SJ, Harrington H, Israel S, et al. The $p$ factor: one general psychopathology factor in the structure of psychiatric disorders? Clin Psychol Sci. 2014;2(2):119-37. https://doi.org/10.11 77/2167702613497473.

26. Lovallo WR. Early life adversity reduces stress reactivity and enhances impulsive behavior: implications for health behaviors. Int J Psychophysiol. 2013;90(1):8-16. https://doi.org/10.1016/j.jpsycho.2012.10.006.

27. McCarty KN, Morris DH, Hatz LE, McCarthy DM. Differential associations of UPPS-P impulsivity traits with alcohol problems. J Stud Alcohol Drugs. 2017; 78(4):617-22. https://doi.org/10.15288/jsad.2017.78.617.

28. Waxman SE. A systematic review of impulsivity in eating disorders. Eur Eat Disord Rev. 2009;17(6):408-25. https://doi.org/10.1002/erv.952.

29. Wolz I, Hilker I, Granero R, Jiménez-Murcia S, Gearhardt AN, Dieguez C, et al. "Food addiction" in patients with eating disorders is associated with negative urgency and difficulties to focus on long-term goals. Front Psychol. 2016;7:61.

30. Kleifield El, Sunday S, Hurt S, Halmi KA. The tridimensional personality questionnaire: an exploration of personality traits in eating disorders. Psychiatr Res. 1994;28(5):413-23. https://doi.org/10.1016/0022-3956(94)90001-9.

31. Lichtenstein MB, Christiansen E, Elklit A, Bilenberg N, Klinky SR. Exercise addiction: a study of eating disorder symptoms, quality of life, personality traits and attachment styles. Psychiatry Res. 2014;250(2):410-6. https://doi. org/10.1016/j.psychres.2013.11.010.

32. Pearson CM, Zapolski TC, Smith GT. A longitudinal test of impulsivity and depression pathways to early binge eating onset. Int J Eat Disord. 2015; 48(2):230-7. https://doi.org/10.1002/eat.22277.

33. Benard M, Bellisle F, Kesse-Guyot E, Julia C, Andreeva VA, Etile F, et al. Impulsivity is associated with food intake, snacking, and eating disorders in a general population. Am J Clin Nutr. 2019;109(1):117-26. https://doi.org/1 0.1093/ajcn/nqy255.

34. Pallister $E$, Waller $G$. Anxiety in the eating disorders: understanding the overlap. Clin Psychol Rev. 2008;28(3):366-86. https://doi.org/10.1016/j.cpr.2 007.07.001.

35. Koven NS, Abry AW. The clinical basis of orthorexia nervosa: emerging perspectives. Neuropsychiatr Dis Treat. 2015;11:385-94. https://doi.org/1 0.2147/NDT.S61665.

36. Lai JS, Hiles S, Bisquera A, Hure AJ, McEvoy M, Attia J. A systematic review and meta-analysis of dietary patterns and depression in communitydwelling adults. Am J Clin Nutr. 2014;99(1):181-97. https://doi.org/10.3945/a jen.113.069880.

37. Strahler J, Hermann A, Schmidt NM, Stark R, Hennig J, Munk AJ. Food cueelicited brain potentials change throughout menstrual cycle: modulation by eating styles, negative affect, and premenstrual complaints. Horm Behav. 2020:104811. https://doi.org/10.1016/j.yhbeh.2020.104811.

38. Obeid S, Lahoud N, Haddad C, Sacre H, Akel M, Fares K, et al. Factors associated with depression among the Lebanese population: results of a cross-sectional study. Perspect Psychiatr Care. 2020;56(4):956-67. https://doi. org/10.1111/ppc.12518.

39. Obeid S, Lahoud N, Haddad C, Sacre H, Fares K, Akel M, et al. Factors associated with anxiety among the Lebanese population: the role of alexithymia, self-esteem, alcohol use disorders, emotional intelligence and stress and burnout. Int J Psychiatry Clin Pract. 2020;24(2):151-62. https://doi. org/10.1080/13651501.2020.1723641.
40. Obeid S, Akel M, Haddad C, Fares K, Sacre H, Salameh P, et al. Factors associated with alexithymia among the Lebanese population: results of a cross-sectional study. BMC Psychol. 2019;7(1):80. https://doi.org/10.1186/s4 0359-019-0353-5.

41. Abou Rizk T. Lebanese Pound's crisis, an opportunity in disguise? 2020. Available from: https://www.bytheeast.com/2020/07/17/lebanese-poundscrisis-an-opportunity-in-disguise/\#: :text=Depreciating\%20currency,at\%2 01\%2C50020against20the\%20greenback.

42. Haddad C, Obeid S, Akel M, Honein K, Akiki M, Azar J, et al. Correlates of orthorexia nervosa among a representative sample of the Lebanese population. Eat Weight Disord. 2019;24(3):481-93. https://doi.org/10.1007/s4 0519-018-0631-X.

43. Haddad C, Hallit R, Akel M, Honein K, Akiki M, Kheir N, et al. Validation of the Arabic version of the ORTO-15 questionnaire in a sample of the Lebanese population. Eat Weight Disord. 2019;25(4):951-60. https://doi. org/10.1007/s40519-019-00710-y.

44. Farchakh Y, Hallit S, Soufia M. Association between orthorexia nervosa, eating attitudes and anxiety among medical students in Lebanese universities: results of a cross-sectional study. Eat Weight Disord. 2019;24(4): 683-91. https://doi.org/10.1007/s40519-019-00724-6.

45. Aoun C, Nassar L, Soumi S, El Osta N, Papazian T, Rabbaa KL. The cognitive, behavioral, and emotional aspects of eating habits and association with impulsivity, chronotype, anxiety, and depression: a crosssectional study. Front Behav Neurosci. 2019;13. https://doi.org/10.3389/ fnbeh.2019.00204.

46. Merz EC, He X, Noble KG. Anxiety, depression, impulsivity, and brain structure in children and adolescents. Neurolmage. 2018;20:243-51. https:// doi.org/10.1016/j.nicl.2018.07.020.

47. Awad E, Obeid S, Sacre H, Salameh P, Strahler J, Hallit S. Association between impulsivity and orthorexia nervosa: any moderating role of maladaptive personality traits? Eat Weight Disord. 2021. https://doi.org/10.1 007/s40519-021-01186-5

48. Mhanna M, Azzi R, Hallit S, Obeid S, Soufia M. Validation of the Arabic version of the Teruel Orthorexia Scale (TOS) among Lebanese adolescents. Eat Weight Disord. 2021. https://doi.org/10.1007/s40519-021-01200-w.

49. Kovaleva A, Beierlein C, Kemper CJ, Rammstedt B. Eine Kurzskala zur Messung von Impulsivität nach dem UPPS-Ansatz: Die Skala ImpulsivesVerhalten-8 (I-8). GESIS-Working Papers, 20; 2012.

50. Obeid S, Abi Elias Hallit C, Haddad C, Hany Z, Hallit S. Validation of the Hamilton Depression Rating Scale (HDRS) and sociodemographic factors associated with Lebanese depressed patients. Encephale. 2018;44(5):397402. https://doi.org/10.1016/j.encep.2017.10.010.

51. Hallit S, Haddad C, Hallit R, Akel M, Obeid S, Haddad G, et al. Validation of the Hamilton anxiety rating scale and state trait anxiety inventory a and $B$ in Arabic among the Lebanese population. Clin Epidemiol Glob Health. 2020;8(4):1104-1109.

52. Malaeb D, Farchakh Y, Haddad C, Sacre H, Obeid S, Hallit S, et al. Validation of the Beirut Distress Scale (BDS-10), a short version of BDS-22, to assess psychological distress among the Lebanese population. Perspect Psychiatr Care. 2021. https://doi.org/10.1111/ppc.12787.

53. Beaton DE, Bombardier C, Guillemin F, Ferraz MB. Guidelines for the process of cross-cultural adaptation of self-report measures. Spine (Phila Pa 1976). 2000;25(24):3186-91. https://doi.org/10.1097/00007632-200012150-00014.

54. Beaton D., Bombardier C., Guillemin F., Ferraz B.. Recommendations for the cross-cultural adaptation of health status measures - supported by the American Academy of Orthopaedic Surgeons, Institute of Work \& Health. 1998. Available from: https://pdfs.semanticscholar.org/729b/fa6c68a48aa fdf61e39e5f999.

55. Al-Bannay $H$, Jarus $T$, Jongbloed L, Yazigi M, Dean E. Culture as a variable in health research: perspectives and caveats. Health Promot Int. 2014;29(3): 549-57. https://doi.org/10.1093/heapro/dat002.

56. George D. SPSS for windows step by step: a simple study guide and reference, 17.0 update, 10/e, Pearson Education India; 2011.

57. Mishra P, Pandey CM, Singh U, Gupta A, Sahu C, Keshri A. Descriptive statistics and normality tests for statistical data. Ann Card Anaesth. 2019; 22(1):67-72. https://doi.org/10.4103/aca.ACA_157_18.

58. Hayes AF. Introduction to mediation, moderation, and conditional process analysis: a regression-based approach, Guilford publications; 2017.

59. Barthels F, Barrada JR, Roncero M. Orthorexia nervosa and healthy orthorexia as new eating styles. PLoS One. 2019;14(7):e0219609. https://doi. org/10.1371/journal.pone.0219609. 
60. Gramaglia C, Brytek-Matera A, Rogoza R, Zeppegno P. Orthorexia and anorexia nervosa: two distinct phenomena? A cross-cultural comparison of orthorexic behaviours in clinical and non-clinical samples. BMC Psychiatry. 2017:17(1):75. https://doi.org/10.1186/s12888-017-1241-2.

61. Heise L, Greene ME, Opper N, Stavropoulou M, Harper C, Nascimento M, et al. Gender inequality and restrictive gender norms: framing the challenges to health. Lancet. 2019;393(10189):2440-54. https://doi.org/10.1 016/50140-6736(19)30652-X.

62. Allen KJD, Sammon MM, Fox KR, Stewart JG. Emotional response inhibition: a shared neurocognitive deficit in eating disorder symptoms and nonsuicidal self-injury. Brain Sci. 2020;10(2). https://doi.org/10.3390/brainsci1 0020104.

63. Claes $L$, Vandereycken $W$, Vertommen $\mathrm{H}$. Impulsivity-related traits in eat-ing disorder patients. Pers Individ Differ. 2005;39(4):739-49. https://doi.org/10.1 016/j.paid.2005.02.022.

64. Luck-Sikorski C, Jung F, Schlosser K, Riedel-Heller SG. Is orthorexic behavior common in the general public? A large representative study in Germany. Eat Weight Disord. 2019;24(2):267-73. https://doi.org/10.1007/s40519-0180502-5.

65. American Psychiatric Associaiton. Statistical manual of mental disorders. Arlington: DSM-V; 2013.

66. Kiss-Leizer M, Toth-Kiraly I, Rigo A. How the obsession to eat healthy food meets with the willingness to do sports: the motivational background of orthorexia nervosa. Eat Weight Disord. 2019;24(3):465-72. https://doi.org/1 0.1007/s40519-019-00642-7.

67. Kesby A, Maguire S, Vartanian LR, Grisham JR. Intolerance of uncertainty and eating disorder behaviour: piloting a consumption task in a non-clinical sample. J Behav Ther Exp Psychiatry. 2019;65:101492. https://doi.org/10.101 6/j.jbtep.2019.101492.

68. Eriksson L, Baigi A, Marklund B, Lindgren EC. Social physique anxiety and sociocultural attitudes toward appearance impact on orthorexia test in fitness participants. Scand J Med Sci Sports. 2007;18(3):389-94. https://doi. org/10.1111/j.1600-0838.2007.00723.x.

69. Tóth-Király I, Gajdos P, Román N, Vass N, Rigó A. The associations between orthorexia nervosa and the sociocultural attitudes: the mediating role of basic psychological needs and health anxiety. Eat Weight Disord. 2021;26: 125-134. https://doi.org/10.1007/s40519-019-00826-1.

70. Strahler J, Hermann A, Walter B, Stark R. Orthorexia nervosa: a behavioral complex or a psychological condition? J Behav Addict. 2018;7(4):1143-56. https://doi.org/10.1556/2006.7.2018.129.

71. Zhunissova M, Shalkarova ZS, Shalkarova ZN, Nuskabayeva G, Sadykova KZ, Madenbay $\mathrm{K}$, et al. Psychoemotional stress and eating behavior in Kazakhstan. Ekologiya Cheloveka. 2015:36-45. https://doi.org/10.33396/17280869-2015-5-36-45

\section{Publisher's Note}

Springer Nature remains neutral with regard to jurisdictional claims in published maps and institutional affiliations.

Ready to submit your research? Choose BMC and benefit from:

- fast, convenient online submission

- thorough peer review by experienced researchers in your field

- rapid publication on acceptance

- support for research data, including large and complex data types

- gold Open Access which fosters wider collaboration and increased citations

- maximum visibility for your research: over $100 \mathrm{M}$ website views per year

At BMC, research is always in progress.

Learn more biomedcentral.com/submissions 